\title{
Pavel Pilch
}

Masarykovo sveučilište u Brnu

pilch@phil.muni.cz

(iD) https://orcid.org/0000-0002-3432-5298

\section{Crni Popaj Štefa Bartolića kao ostvarenje moralne periferije}

Sažetak: Ovaj se rad bavi interpretacijom stripovnog lika Crnog Popaja čiji je autor Štef Bartolić. Kontroverzni lik tog fikcionalnog nasilnika shvaćamo donekle kao metaforu ekstremnog poimanja slobode koja, unatoč njegovoj odvratnoj naravi, govori više o našim moralnim pravilima nego zakonski propisi i etička načela. Pojave poput droga, seksualnog zlostavljanja i nasilja u okviru našeg metaforičkog razmišljanja shvaćamo kao iskrivljeno zrcalo koje, usmjereno prema našoj svakodnevici, otkriva pravu narav čovjeka koji još nije istupio iz životinjskog univerzuma.

Ključne riječi: Crni Popaj, moral, zakon džungle, hrvatski strip, Štef Bartolić

U svome se radu posvećujemo Crnom Popaju, jednom od najzanimljivijih hrvatskih stripovnih likova, koji inspiraciju crpi iz pustolovina američkog pomorca poznatog širom svijeta koji se zove samo Popaj (engl. Popeye). Crni Popaj zanimljiv je prije svega po tome što utjelovljuje kontroverzije povezane s općim moralnim pitanjima svakodnevice, no ne radi se o običnim pitanjima dobra, zla ili pravde, nego o konkretnijim pitanjima čija srž zna dovesti do burnih društvenih diskusija i prepucavanja. Bilo da se radi o drogama, nasilju, maltretiranju žena ili nekrofiliji, sva ta pitanja nalaze se na granici onoga što je dopustivo, a dobrim dijelom i iza nje. Moralna periferija po našem mišljenju označava prostor na kojem se ostvaruju najcrnje mogućnosti moralnih dilema.

Međutim Crni je Popaj lik koji je ključno povezan s hrvatskim stripovnim podzemljem, dakle s kulturnom periferijom. Nastao je 1992. godine u jednom od ateljea zagrebačkog Grafičkog fakulteta. Ondje 
je izlazio studentski časopis Grafomanija, koji je prvi put ugostio lik Crnog Popaja. Osim u Grafomaniji pojavljivao se između 1992. i 2003. godine uglavnom u stripovnim i umjetničkim časopisima kao što su Puls, Čempres, Reporter, Reporterov Comixer, Bruh ili Nomad, odnosno u anarhističkim i pankerskim fanzinima poput Stripoholica, Porno Smeća Radikala ili Države. Pojavio se čak i u najtiražnijim novinama i časopisima kao što su Večernji list, Slobodna Dalmacija i Nacional. ${ }^{1}$ Njegov prodor iz stripovnoga undergrounda na stranice dnevnog tiska trajao je kratko, no u hrvatskom stripovnom stvaralaštvu ostavio je važan trag.

Crni je Popaj bio, važno je spomenuti, kolektivna tvorevina u izradi crteža i scenarija njegovih pustolovina sudjelovalo je desetak autora, među kojima se posebno ističu doajen suvremenog hrvatskog stripa Darko Macan, ${ }^{2}$ u naslovu našega rada već spomenuti Stjepan „Štef“ Bartolić te Satan Panonski, ${ }^{3}$ koji je autor nekoliko scenarija. Pojavivši se u okvirima hrvatskog stripovnog undergrounda, Crni je Popaj najprije bio utjelovljenje buntovništva u stilu pankerske estetike: od tipične pankerske frizure i odjeće preko načina preživljavanja na ulicama ratne i poslijeratne Hrvatske do odnosa prema vlasti, policiji i zakonu. Crni je Popaj lik poremećenog karaktera koji ne mari za štete koje ostavlja za sobom ako ima što pušiti i piti.

Deset godina Crnog Popaja i njegovih pustolovina koje su bile razbacane po raznim časopisima i fanzinima sažela je antologija Crni Popaj: Rekapitulacija objavljena 2003. godine na inicijativu nakladnika Novo hrvatsko podzemlje. Autori antologije, skriveni iza anonimnih nadimaka, opisali su Crnog Popaja ovim riječima:

Crni je Popaj hrabro, kao nitko prije ili poslije njega, stupio na pozornicu ne mareći o tome da li će ga narod zakucati na kitu srama ili ga doživotno nositi na rukama okrunjenog vijencima lovora i drugih vrhunskih hortikulturnih dostignuća ljudske civilizacije. Bolio ga je kurac! ${ }^{4}$

\footnotetext{
${ }^{1}$ Anonymous, ur., Crni Popaj: Rekapitulacija (Zagreb: Novo hrvatsko podzemlje, 2003), 8.

${ }^{2}$ Darko Macan (1966-) profesionalni je autor i urednik stripovnih knjiga, jedan od najvažnijih likova suvremenog hrvatskog stripa. Izdavao je legendarni magazin za strip $Q$-strip, dobitnik je brojnih nagrada, piše i crta za francusko tržište.

${ }^{3}$ Satan Panonski, pravo ime Ivica Čuljak (1960-1992), bio je hrvatski pank-pjevač poznat po ekscentričnom ponašanju i performansima. Poginuo je kao vojnik Hrvatske vojske tijekom borbi u Vinkovcima. Njegov život i djelo inspiracija su za stripovni lik Malog Ivice iz stripova Dubravka Matakovića.

${ }^{4}$ Anonymous, Crni Popaj, 8.
} 
Lik Crnog Popaja često se referirao na Hrvatsku odnosno Jugoslaviju, na njezinu kulturu, politiku, povijest, narode i nacije i sl. Tako je na primjer ljetovao na Hvaru, rugao se poznatome autoru partizanskih stripova Julesu, ${ }^{5}$ opijao se s urednicima stripovnih časopisa poput Krešimira Zimonića, ${ }^{6}$ obrađivao tekstove Dead Kennedysa, referirao se na hrvatsku kinematografiju itd. Osim kritici društva i društvenih pojava pokazao se sklonim alkoholu, drogama, psovci, seksu na sve moguće načine i nečemu što bismo mogli nazvati „fekalnim oružjem“ u psovačkom i doslovnom smislu. Nije nikakvo čudo da je špinat, omiljena biljka američkog Popaja, u pustolovinama Crnog Popaja zamijenjen jednom drugom biljkom čiji latinski naziv glasi cannabis.

Istini za volju, kvaliteta pojedinih stripova veoma je različita, bilo na razini crteža bilo na razini scenarija. S jedne strane nalazimo odlične viceve kojima nedostaje spretna crtačka ruka, dok s druge strane često nailazimo na izvrstan crtež bez ikakve scenarističke ideje. Naravno, ima iznimaka koje potvrđuju pravilo: primjerice Darko Macan i odlično crta i ima duhovite i originalne viceve. Međutim najbolje je ostvarenje Crnog Popaja ono Stjepana Bartolića, poznatijeg pod nadimkom Štef, čiji je originalni crtački stil toliko upečatljiv da je njegovu Crnom Popaju bio posvećen poseban broj magazina $Q$-strip u kojem su tiskane tri dulje priče koje su predmet analize u ovome radu.

Bartolić, rođen 1967. godine u Zagrebu, bio je povezan s hrvatskom pankerskom scenom, jedan od njegovih najcjenjenijih stripova, Gluhe laste, govori o pankerskom bendu koji se devedesetih godina bori ne samo za vlastiti opstanak i uspjeh nego i protiv vladavine gluposti i licemjerja. Njegov Crni Popaj iznimna je pojava, semiotički sočna priča koja ne govori samo o nekom modernom društvu, nego njegov glavni lik komunicira preko oceana sa svojim bratićem, pomorcem Popajem, koji je u određenom smislu problematičan jednako kao Bartolićev Crni Popaj.

Pomorac Popaj E. C. Segara, koji je inspiracija Crnom Popaju, prvi se put pojavio 1929. godine u stripu Thimble Theatre i odmah postao jedan od najpopularnijih crtanih likova u SAD-u. ${ }^{7}$ Kasnije je bio junak

\footnotetext{
${ }^{5}$ Jules, pravo ime Julio Radilović (1928-), jedan je od najpoznatijih crtača stripova na prostoru bivše Jugoslavije. Svjetski poznat postao je sa stripovima Herlock Sholmes i Partizani. Godine 2010. dobio je nagradu „Andrija Maurović“ za životno djelo i doprinos hrvatskome stripu.

${ }^{6}$ Krešimir Zimonić (1956-) bio je član poznate grupe stripovnih umjetnika Novi kvadrat, urednik nekoliko stripovnih časopisa i predstavnik mlađeg naraštaja Zagrebačke škole crtanoga filma. Njegova Zlatka jedna je od najpoznatijih junakinja hrvatskoga stripa.

7 The Editors of Encyclopaedia Britannica, ur., „Popeye,“ Encyclopaedia Britannica, 26. srpnja 2019, pristupljeno 30. ožujka 2020, https://www.britannica.com/topic/Popeye.
} 
crtanih i igranih filmova, no njegovo je porijeklo iz stripa, što većina gledatelja crtanih filmova ne zna. U Drugom svjetskom ratu postao je heroj američke propagande. Taj je period njegova života najkontroverzniji. Tada se poput mnogih drugih junaka stripa (Kapetan Amerika, Superman i sl.) pojavljivao u propagandnim filmovima i stripovima koji su na ksenofoban način prikazivali pripadnike drugih naroda, ponajprije onih s kojima je SAD zaratio. Primjerice Japanci su prikazivani kao lukave kukavice i mongoloidne životinje, što nije neuobičajeno kada se radi o grafičkoj propagandi, a može se usporediti s prikazivanjem Židova u nacističkoj Njemačkoj ili Nijemaca u partizanskom stripu bivše Jugoslavije, odnosno s prikazivanjem Srba u hrvatskim ratnim stripovima iz 90-ih godina 20. stoljeća (naravno da vrijedi i obrnuto).

Najjači udarac Popaj je pretrpio početkom 21. stoljeća kada je utvrđeno da izvor njegove snage - špinat - uopće ne sadrži toliko željeza koliko se mislilo, nego deset puta manje. Tim mitom o špinatu nije se koristio samo Popaj, već i češki film Což takhle dát si špenát iz 1977. godine. Znanstvenici su za tu „laž“ znali još u tridesetim godinama prošloga stoljeća, no cijela se priča proširila tek zahvaljujući internetu sedamdeset godina poslije. ${ }^{8}$ Međutim nova istraživanja o špinatu iz 2012. godine pokazala su da je zapravo priča o maloj količini željeza u špinatu bila lažna, no mit o njemu već je cirkulirao svijetom, a Popaja više nitko nije izvukao iz groba.

Bartolićeva Crnog Popaja s američkim pomorcem povezuje i njegovo društvo, uglavnom Badžo (engl. Bluto) i Oliva (engl. Olive), koji se kod drugih crtača Crnog Popaja gotovo ne pojavljuju. Karakteristike tih triju likova, za razliku od originala, potpuno su iskrivljene. Popaj je nasilan, okrutan, bezobziran, nepristojan, narkoman i alkoholičar koji redovno tuče svoju djevojku. Oliva je rezignirana žena koja dopušta Popaju da je zloupotrebljava, dok je Badžo, koji je zaljubljen u Olivu, dobar i brižan momak koji podnosi sve udarce od života kako bi Olivi pomogao da preživi pakao koji joj priređuje Popaj.

Popajev lik utjelovljuje neke od ljudskih osobina koje sigurno ne smatramo pozitivnima. Na prvom je mjestu njegova nasilnička narav. Dok američki Popaj sa svojim krivim nogama i nespretnim rukama izgleda kao bolesnik, a do snage dolazi tek nakon konzumacije špinata, Bartolićev je Popaj gomila mišića kojoj se suprotstavljaju samo oni najhrabriji ili najgluplji. Čak ni njegovo lice bez oka ne izaziva sućut, nego

\footnotetext{
${ }^{8}$ Lydia Ramsey Pflanzer, „Spinach doesn’t have as much of a key nutrient needed in your blood as you might think,“ Business Insider, 16. lipnja 2017, pristupljeno 30. ožujka 2020, https://www.businessinsider.com/spinach-iron-levels-nutrition-myths-2017-6.
} 
strah ili gađenje. Crni Popaj nikad ne razmišlja o mirnom rješavanju situacije, čak je ponosan na to što tuče svoju djevojku, kojoj mora „nabubriti usne jer nisu pušačke“ (vidi sliku 1), te svoje „prijatelje“ i nepoznate ljude, kao da je lik iz Zonijeve pjesme koji „voli kada bježe / gazi kada leže“.9 Takav ga bijes obuzima uglavnom kad nema droge ili novca za nju. Možemo dakle reći da je droga dio njegova identiteta.

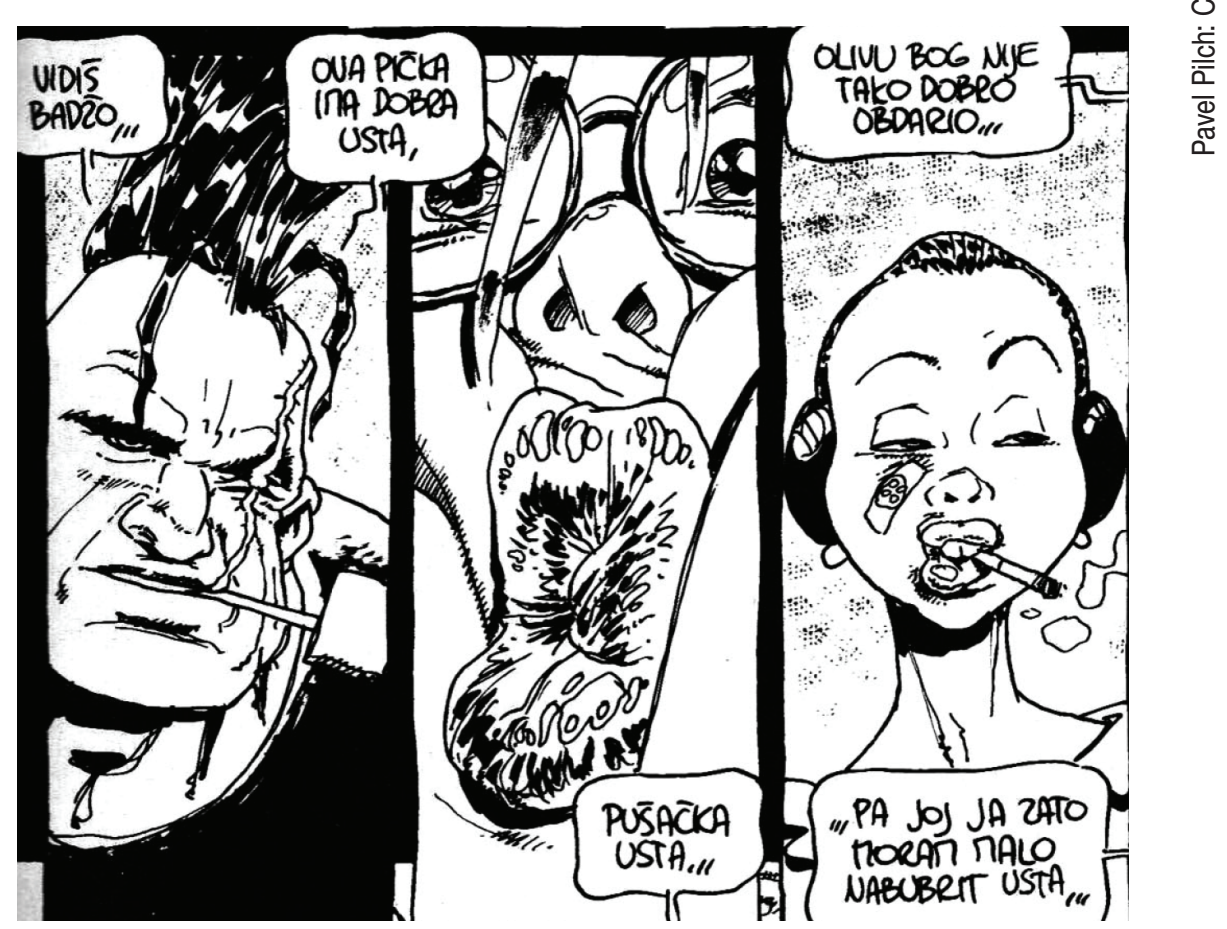

Slika 1. Štef Bartolić, Crni Popaj (Zagreb: Mentor, 2008)

Popajeva nasilna narav najviše dolazi do izražaja u njegovu odnosu prema ženama. On je najgore oličenje mizoginije i mačizma, što pokazuje odnos prema njegovoj djevojci Olivi čiji je život posve upropastio. Upoznao ju je tako što ju je silovao pred Badžom iako je znao da je Badžo u nju zaljubljen. To je poveznica s američkim Popajem, s tom razlikom što je američki Badžo okrutan i mizogin, dok je Bartolićev dobar, nježan i pacifist. Popaj je Olivu „navukao na iglu“, dakle postala je ovisna ne samo o drogi nego i o njemu koji pribavlja novac i kupuje drogu za oboje. Popajeva mizoginija prikazana je u sceni u kojoj siluje Badžinu djevojku u WC-u kluba tijekom koncerta, dok Badžo ispod pozornice moli Olivu da ostavi Popaja. Popaj ga uhvati

\footnotetext{
${ }^{9}$ Dječaci, Istina (Zagreb: Croatia Records, 2011).
} 


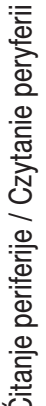

na djelu i istuče ga tako da Badžo ostane bez svijesti, a poslije ga ubije u bolnici. Vrhunac je Popajeve okrutnosti i brutalnosti scena u kojoj dolazi u crkvu na Olivinu sahranu i siluje njezin leš. Kad završi, odlazi uz riječi „Moje saučešće!“‘ (vidi sliku 2). Nitko od prisutnih ni prstom ne mrdne kako bi ga spriječio u tom odvratnom činu. Moralna nakaza Crni Popaj jednostavno, kao i njegov američki rođak, uvijek pobjeđuje, s tom razlikom što se Crni Popaj ne brine zbog „,kolateralne štete“, koja je golema i nepopravljiva.

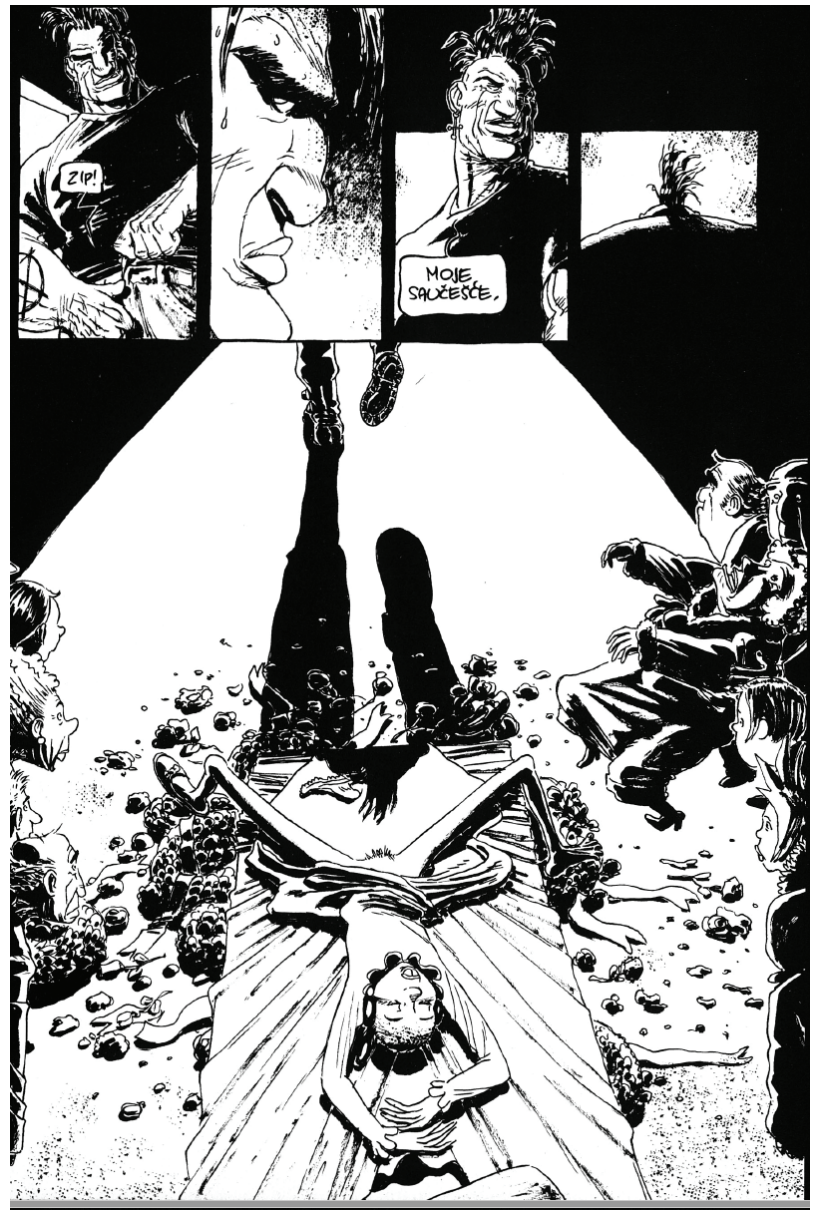

Slika 2. Bartolić, Crni.

Postavlja se pitanje kako uopće interpretirati lik Crnog Popaja. On nije simpatičan gangster, poput junaka Tarantinovih filmova, ni ambivalentan junak crne duše kojeg, iako ga ne prihvaćamo, možemo donekle razumjeti. Bartolićev je Crni Popaj jednostavno utjelovljenje 
zla. Možemo ga u određenoj mjeri smatrati simbolom suvremenog vremena - brutalnom silom koja iz sebične koristi gazi po životima drugih ne obazirući se na štetu koju pravi. Silom koja ne poštuje društvo, državu, vlast ni zakone, osim zakona džungle koji Hrvatski jezični portal definira kao „stanje bezakonja, nasilja, zakon jačega“" ${ }^{10}$ a to je upravo Popajev slučaj.

Vratimo se na trenutak naslovu našeg rada i pitanju: gdje je moral? Crnom Popaju taj je pojam nepoznat, on slijedi neki svoj kodeks koji uglavnom sadrži jedno pravilo: radi što god hoćeš, a za druge ne mari. Popaj kao crna sila zgazi sve što možemo smatrati civiliziranim, dobrim odnosno moralnim. Ne poznaje ni sućut ni empatiju, a najgore je od svega to što ga društvo u kojem živi mrzi, ali u isto vrijeme šuti.

Uostalom, već naslovnica stripa zorno prikazuje Popajevo društvo i odnos između njega i njegovih prijatelja - Badžo, Oliva i svi drugi su nasmijani, dok su im lica umazana krvlju, a Popajevi su zglobovi oblijepljeni flasterima (vidi sliku 3). Crni je Popaj proizvod društva koje je izgubilo svoju bazu, izrastao je kao najsebičniji sebičnjak među sebičnjacima, a da je bio samo malo pametniji, otišao bi u visoku politiku ili postao tajkun ili mafijaš. No njegova je ideologija kaotični anarhizam, nisu mu simpatični nikakvi oblici društvenog sustava ili hijerarhije i od subverzije brzo se okrenuo (samo)destrukciji. Crni Popaj nije utjelovljenje moralne propasti samo kao stripovni ili fikcionalni lik, nego i sâm strip provocira izborom tema - nasilje, seksualne perverzije, mizoginija, droga, ubojstva itd. subverzivno djeluju protiv stripovnog mainstreama u kojem uvijek pobjeđuju Superman i njemu slični (super)heroji. No u priči o odbojnom liku pred kojim svi kleče ipak nalazimo malo nade. Naime i Popaja je stigla neka vrsta karme, te on umire na isti način kao što je ubio svog prijatelja Badžu - njegov mu nazoviprijatelj Oskar zbog sitnog novca za drogu smrska lice palicom.

Crnoga Popaja moramo čitati na drugačiji način od onoga koji nam se sam po sebi nameće: moramo ga čitati kao metaforu. Crni je Popaj prije svega urlik u uho nagluhoga društva koje je zaspalo u iluziji o vlastitoj savršenosti. No ništa nije savršeno, naprotiv: svijet Crnoga Popaja ekstreman je laboratorij koji pokazuje mane našeg društva.

\footnotetext{
${ }^{10}$ Hrvatski jezični portal, „Džungla,“ pristupljeno 30. ožujka 2020, http://hjp.znanje.hr/index.php?show=search_by_id\&id=fF5hXBQ\%3D\&keyword=d\%C5\%BEungla.
} 


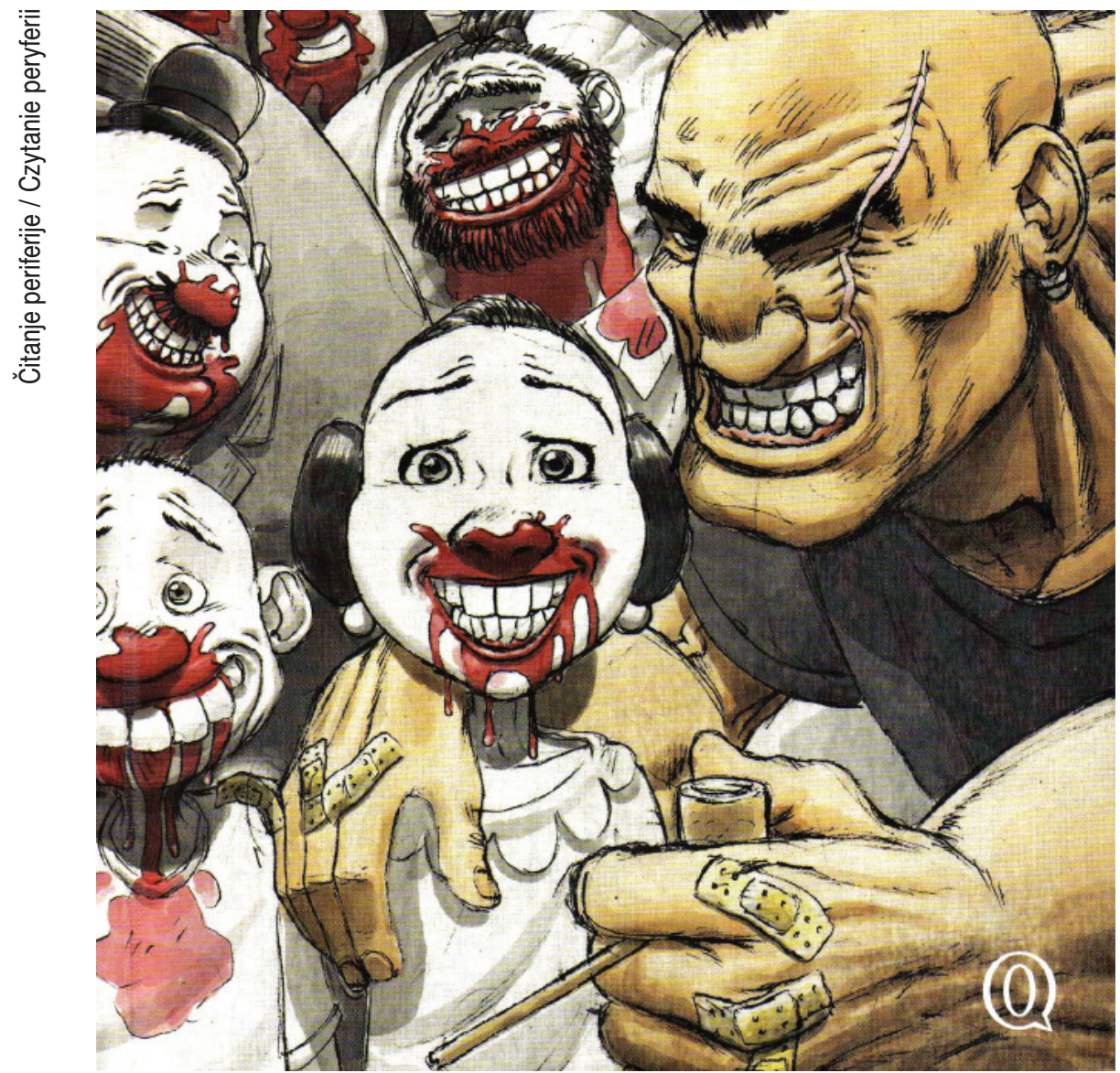

Slika 3. Bartolić, Crni.

On u sebi sadrži i hrani najgore ostatke barbarstva koji još uvijek žive u našoj sredini. Dok je pažnja usredotočena na drogu ili nasilje, marginalizirano je postupno preuzimanje moći onih koji posjeduju medije, kapital ili političku moć. Crni je Popaj apolitičan lik u smislu da mu nije prihvatljiva nikakva politička doktrina. Njegov je anarhizam izraz totalne slobode. Ta je sloboda, doduše, izopačena jer ugrožava slobodu drugih, ali unatoč tomu Popaj ostaje najslobodnijim čovjekom u svome fikcionalnom svijetu, a to je ono što zabrinjava. Naime volimo se smatrati civiliziranima, dok nam Popaj bezobzirno kaže da smo još uvijek životinje. Svakodnevna borba za opstanak nalik je na borbu za život u divljoj prirodi, ljudi umiru od gladi zbog neimaštine, dok drugi žderu u svojim zlatnim palačama. Popajev kažiprst upozorava na nepravdu s kojom se svakog jutra budimo, no ujedno nam njime želi 
iskopati slijepe oči kako bismo bolje vidjeli. Nemojmo se plašiti njegova brutalnog ponašanja, ono je samo maska iza koje se krije neugodna istina.

Crni je Popaj, ponovimo na kraju, moralna nakaza, moralno upitan lik, utjelovljenje najgorih ljudskih osobina, a može se čitati i kao metafora bezobzirnosti koja vlada određenim (uglavnom ekonomski motiviranim) društvenim odnosima svakidašnjice, s jednom bitnom razlikom: Popaja se može lako identificirati pa ga izbjegavati, zatvoriti korice knjige, ostaviti ga na polici knjižnice, dok to, nažalost, ne možemo učiniti s licemjerjem koje vlada našim životima. Crni Popaj, iako odvratan i gnusan, sadrži onu vrijednost koju pripisujemo umjetnosti: zna uperiti prst u ono što smo navikli zanemarivati, prezirati i zaboravljati, a to je istina da su naša društva još uvijek daleko od moralnih ideala kojima teže.

\section{Literatura}

Anonymous, ur. Crni Popaj: Rekapitulacija. Zagreb: Novo hrvatsko podzemlje, 2003.

Bartolić, Štef. Crni Popaj: posebno izdanje časopisa Q-strip. Zagreb: Mentor, 2010.

Booker, M. K., ur. Encyclopedia of Comic Books and Graphic Novels. Santa Barbara: Greenwood, 2010.

Dječaci, Istina. Zagreb: Croatia Records, 2011.

Hrvatski jezični portal. „Džungla.“ Pristupljeno 30. ožujka 2020. http://hjp.znanje. $\mathrm{hr} /$ index.php?show=search_by_id\&id=fF5hXBQ\%3D\&keyword $=\mathrm{d} \% \mathrm{C} 5 \% \mathrm{BE}$ ungla.

Ramsey Pflanzer, Lydia. „Spinach doesn't have as much of a key nutrient needed in your blood as you might think.“ Business Insider, 16. lipnja 2017. Pristupljeno 30. ožujka 2020. https://www.businessinsider.com/spinach-iron-levelsnutrition-myths-2017-6.

The Editors of Encyclopaedia Britannica, ur. „Popeye.“ Encyclopaedia Britannica, 26. srpnja 2019. Pristupljeno 30. ožujka 2020. https://www.britannica.com/ topic/Popeye.

\section{Black Popeye by Štef Bartolić as a Realisation of Moral Periphery}

Summary: This text deals with the interpretation of the comic character Crni Popaj (Black Popeye) written and drawn by Štef Bartolić. We find the controversial personality of this fictional abuser as somewhat of a metaphor for the extreme conception of freedom, which, despite its disgusting nature, speaks more to our 

:- moral rules than laws and ethical principles. Phenomena such as drugs, sexual त्र mirror that, directed toward our daily lives, reveals the true nature of man who has not yet emerged from the animal universe.

엉 Keywords: Crni Popaj, morality, jungle laws, Croatian comics, Štef Bartolić 